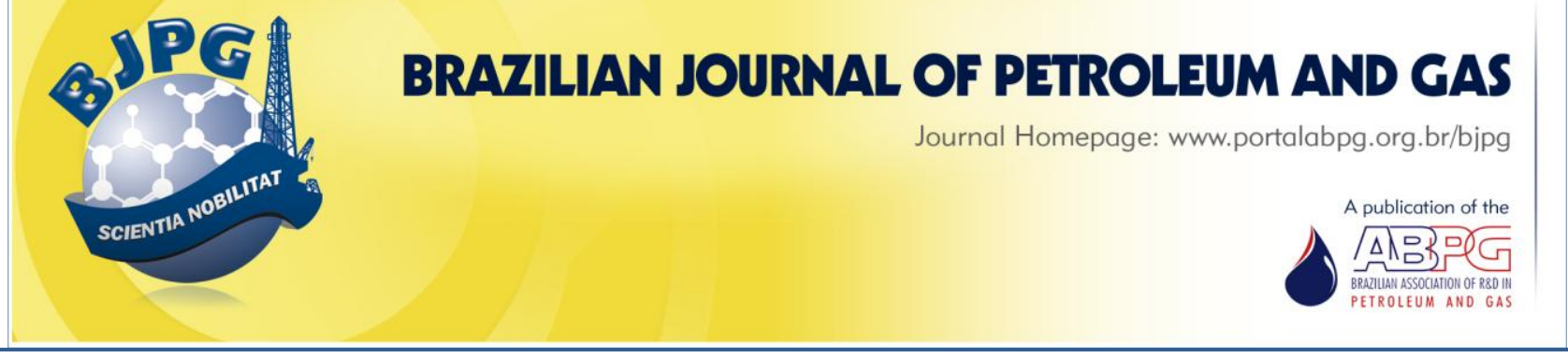

\title{
CHARACTERIZATION OF HOLLOW FIBRE MEMBRANES FOR OXYGEN PERMEATION AND PARTIAL OXIDATION REACTIONS
}

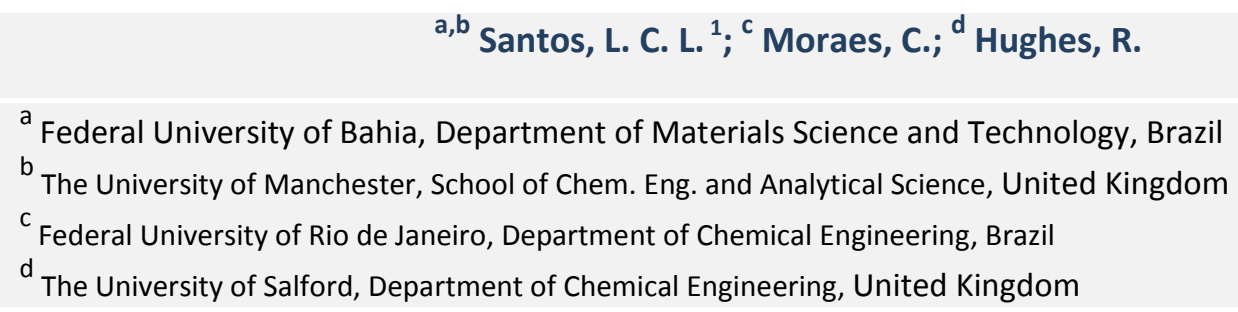

\begin{abstract}
Experimental results regarding characterization of BSCF 5582 and LSCF 6428 in the form of hollow fibres are presented in this work. These are membranes that can be potentially used in applications such as oxygen permeation and syngas production. In the case of LSCF 6428 hollow fibres, a surface modification was proposed giving two different morphology structures which were called as "smooth" and "rough" surface. Three main techniques were used to characterize these membranes: X-ray diffraction (XRD) analysis, energy dispersive $X$-ray emission analysis (EDAX) and scanning electron microscopy (SEM). A large distribution of cavities was observed on the surface of BSCF 5582, which might be a concern for obtaining a gas-tight membrane. In the case of LSCF 6428, both morphologies present a structure filled with elongated finger-like cavities close to both outer and inner surface, which can be explored in catalyst impregnation. In addition, the rough surface structure is fairly spongy which might be of interest for catalyst impregnation and surface kinetic studies.
\end{abstract}

\section{KEYWORDS}

Ceramic membrane; hollow fibres; perovskite; oxygen permeation; partial oxidation reaction

\footnotetext{
${ }^{1}$ To whom all correspondence should be addressed.

Address: Federal University of Bahia, Escola Politécnica, DCTM, Rua Professor Aristides Novis 02, 3 Andar, Federação, CEP 40210-630, Salvador/BA, Brazil

Telephone/Fax: +55 71 3283-9854/+55 71 3283-9835 | e-mail: Iclsantos@ufba.br doi:10.5419/bjpg2011-0006
} 


\section{INTRODUCTION}

Membrane characterization is one of the crucial aspects that need to be accounted for when its structural and morphological properties must be determined. Different preparation techniques may provide different membrane structures, and each kind of structure is responsible for solving a specific separation problem (Mulder, 1996).

The general formula for perovskite, for example, is $\mathrm{ABO}_{3}$, with $\mathrm{CaTiO}_{3}$ being a typical compound. Here, large cations are present which can form a close-packing structure along with oxygen ions. $\mathrm{Ca}^{2+}$ and $\mathrm{O}^{2-}$ ions combine to form a cubic close-packing (CCP) structure with the smaller and highly charged $\mathrm{Ti}^{4+}$ ions in octahedral interstices. Substitutions are possible both on the $A$ and on the B sites (Gellings and Bouwmeester, 1992).

The highest oxygen permeation flux using $\mathrm{La}_{1-}$ ${ }_{x} \mathrm{Sr}_{x} \mathrm{Co}_{1-y} \mathrm{Fe}_{y} \mathrm{O}_{3-\delta}$ series was obtained with $\mathrm{x}$ equal to 1 and y equal to 0.2 (Teraoka et al., 1985a). The total substitution of the cation metal $\mathrm{La}^{+3}$ by $\mathrm{Sr}^{+2}$ allowed the creation of an oxygen vacancy in the lattice which caused an increase in the oxygen flow rate through the membranes. An oxygen permeation flux as high as $3.38 \mathrm{~mL}(\mathrm{STP}) / \mathrm{cm}^{2}$. $\mathrm{min}$ at 850 ㅇ $\mathrm{C}$ was obtained by the researchers using a disc membrane with $10 \mathrm{~mm}$ diameter and $1 \mathrm{~mm}$ thickness. Due to the high oxygen permeability observed using $\mathrm{SrCO}_{0.8} \mathrm{Fe}_{0.2} \mathrm{O}_{3-\delta}$ membrane, Pei et al. (1995) have applied this structure in the partial oxidation of methane to syngas. Unfortunately, they observed that this membrane is chemically and mechanically unstable under reducing atmospheres. Shao et al. (2000) partially replaced $\mathrm{Sr}^{+2}$ in $\mathrm{SrCO}_{0.8} \mathrm{Fe}_{0.2} \mathrm{O}_{3-\delta}$ with $\mathrm{Ba}^{+2}$ resulting a material with higher phase stability. The oxygen permeation flux has also been slightly improved (Shao et al., 2001a) with this modification. The influence of $\mathrm{Ba}$ doping on the $\mathrm{Ba}_{x} \mathrm{Sr}_{1-x} \mathrm{Co}_{0.8} \mathrm{Fe}_{0.2} \mathrm{O}_{3-\delta}$ series was studied by Shao et al. (2001b) and it was observed that $0.3 \leq \mathrm{x} \leq 0.5$ is the optimal Ba doping content. In this range, the perovskite structure was sustained and high oxygen permeation flux could be obtained. Dong et al. (2001) have studied the $\mathrm{Ba}_{0.5} \mathrm{Sr}_{0.5} \mathrm{Co}_{0.8} \mathrm{Fe}_{0.2} \mathrm{O}_{3-8}$ membrane (BSCF 5582) in the partial oxidation of methane using disc membranes of $1.13-\mathrm{cm}$ diameter and $1.48-\mathrm{mm}$ thickness and LiLaNiO $/ \gamma-\mathrm{Al}_{2} \mathrm{O}_{3}$ with $10 \mathrm{wt} . \% \mathrm{Ni}$ loading as a catalyst. At $875 \stackrel{\circ}{\circ}$, an oxygen permeation flux of about $11.2-11.8 \mathrm{~mL} / \mathrm{cm}^{2}$. min was observed with a methane conversion of $97-98 \%$ and carbon monoxide selectivity of $95-97 \%$.

For the reasons presented previously, the BSCF 5582 was selected as a promising material which can be used in partial oxidation reactions.

Regarding LSCF 6428, Teraoka et al. (1985a,b) were the first researchers to study oxygen permeation through $\mathrm{La}_{1-x} \mathrm{Sr}_{x} \mathrm{CO}_{1-y} \mathrm{Fe}_{y} \mathrm{O}_{3-\delta}$ perovskitetype oxides. The partial substitution of $\mathrm{Fe}$ with $\mathrm{Co}$ on the $\mathrm{La}_{1-\mathrm{x}} \mathrm{Sr}_{x} \mathrm{CoO}_{3-\delta}$ perovskite enhanced both oxygen desorption and the catalytic activity. In addition, high oxygen permeation flux can be obtained by varying the $x$ and $y$ contents in the $\mathrm{La}_{1}$. ${ }_{x} \mathrm{Sr}_{x} \mathrm{Co}_{1-y} \mathrm{Fe}_{y} \mathrm{O}_{3-\delta}$ series. Since then, the oxygen permeability and the ionic and electronic properties of the $\mathrm{La}_{1-x} \mathrm{Sr}_{x} \mathrm{CO}_{1-y} \mathrm{Fe}_{y} \mathrm{O}_{3-\delta}$ series have been thoroughly investigated.

Great interest has been focused on the $\mathrm{La}_{0.6} \mathrm{Sr}_{0.4} \mathrm{Co}_{0.2} \mathrm{Fe}_{0.8} \mathrm{O}_{3-\delta}$ (LSCF 6428) membrane due to its high degree of chemical and mechanical stability (Jin et al., 2000a). In addition, high ionic and electronic conductivities can be observed using LSCF 6428 membrane. The formula of complex perovskites are often abbreviated using the first letter of the element symbol of each of the metal cation components. This is followed by a list of numbers which correspond to the first significant figure of the stoichiometry of the respective metal cation. This system is not official and variations do occur in the literature.

Oxygen transport through dense LSCF 6428 membranes has been investigated in the literature using mainly disc membranes due to the simplicity of their fabrication. Lane et al. (1999) investigated oxygen transport in LSCF 6428 using disc membranes of $25 \mathrm{~mm}$ diameter and $0.96-\mathrm{mm}$ thickness. The oxygen permeation study was performed using helium and air at either side of the ceramic membrane. At 800 o $C$ an oxygen permeation flux of $0.04 \mathrm{~mL} / \mathrm{cm}^{2}$. min could be observed - whilst the authors report fluxes in volumetric terms, in this work we report the conditions of temperature and pressure applied to each flux only if the authors have reported such conditions. Tubular membranes have also been used in oxygen permeation studies and syngas production, but not as frequently as disc membranes. Li et al. (1999) investigated the oxygen permeation properties of a tubular LSCF 
6428 membrane with a uniform wall thickness of $1.5 \mathrm{~mm}$. Air was flowing in the shell-side while helium was flowing in the lumen-side (shell-side refers to the outer surface and lumen-side refers to

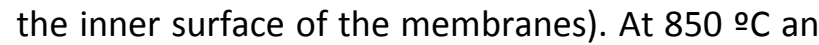
oxygen permeation flux of $0.14 \mathrm{~mL}(\mathrm{STP}) / \mathrm{cm}^{2}$. $\mathrm{min}$ was observed. Partial oxidation of methane has been investigated by Jin et al. (2000b) using a tubular LSCF 6428 membrane packed with $\mathrm{Ni} / \mathrm{Al}_{2} \mathrm{O}_{3}$. The membrane had an $8-\mathrm{mm}$ outer diameter, $15-\mathrm{cm}$ length and $1.5-\mathrm{mm}$ thickness. Air was supplied to the shell-side of the reactor and methane diluted in helium was supplied in the lumen-side. It was observed that, in the range of 825-885 ㅇ $C$ and at low carbon space velocity, methane conversion higher than $96 \%$ and carbon monoxide selectivity higher than $97 \%$ were obtained.

The reported oxygen permeation flux obtained using disc and tubular membranes might be improved by looking into different membrane geometries. In this sense, hollow fibres appear as a promising membrane geometry, since it can provide a much higher surface area per unit volume (Thursfield and Metcalfe, 2006).

In this work, $\mathrm{Ba}_{0.5} \mathrm{Sr}_{0.5} \mathrm{Co}_{0.8} \mathrm{Fe}_{0.2} \mathrm{O}_{3-\delta}$ (BSCF 5582) and $\mathrm{La}_{0.6} \mathrm{Sr}_{0.4} \mathrm{Co}_{0.2} \mathrm{Fe}_{0.8} \mathrm{O}_{3-\delta}$ (LSCF 6428) were chosen as good mixed ionic-electronic ceramic membranes which can be used in several applications such as oxygen permeation and syngas $\left(\mathrm{H}_{2}+\mathrm{CO}\right)$ production. The BSCF 5582 perovskite material was chosen because of its excellent ionic and electronic properties (Dong et al. 2001; Shao et al. 2001a; Shao et al. 2001c; Tan et al. 2003; Wang et al. 2002). LSCF 6428 is a classical material widely studied in the literature. It also presents relatively high ionic and electronic conductivity associated with great mechanical and chemical stability (Lane et al., 1999).

It is known that pure oxygen is required for the partial oxidation of methane (POM) to syngas (Neiva and Gama, 2010), which is the first stage to convert natural gas into liquid fuels, such as gasoline or diesel, free of sulphur and aromatics. If POM is combined with ceramic membrane technology, the costs associated with this method could be dramatically reduced. Dense ceramic membranes with the perovskite phase structure can be used as selective separators of oxygen from air, minimizing costs related with the purification of oxygen. Therefore, it is the aim of this contribution to show the experimental results regarding characterization of BSCF 5582 and LSCF 6428 perovskite membranes, in the form of hollow fibres, and to relate them with oxygen permeation and partial oxidation reaction.

\section{EXPERIMENTAL}

\subsection{Preparation of the hollow fibre membranes}

The BSCF 5582 and LSCF 6428 powders used to prepare the hollow fibre membranes were purchased from Praxair Specialty Ceramics. They were formed by combustion spray pyrolysis (CSP) and were used without further treatment.

The hollow fibres were prepared by a combined phase-inversion/sintering technique in the Department of Chemical Engineering \& Chemical Technology, at the Imperial College / London. The adopted preparation technique basically consisted of mixing the commercial powders (using an uniform particle size distribution of $c a 1 \mu \mathrm{m}$ ) with a polymer solution for $48 \mathrm{~h}$, which was then passed through a tube-in-orifice spinneret using tap water as internal and external coagulants. In order to complete the solidification, the hollow fibre precursors were immersed in a water bath. The green hollow fibres were then sintered at 1280 ㅇ $\mathrm{C}$ for $4 \mathrm{~h}$ giving an outer diameter of $c a 1.5 \mathrm{~mm}$, an inner diameter of $c a 1 \mathrm{~mm}$ and a nominal length of $25 \mathrm{~cm}$. A detailed preparation technique is described elsewhere (Liu et al., 2001; Tan et al., 2005).

In the case of LSCF 6428 hollow fibres, surface modification was proposed for its preparation by using a ceramic powder consisting of a mixture of particles with different sizes. The particle size distribution was $0.4 \mu \mathrm{m}$ (d10), $0.6 \mu \mathrm{m}$ (d50) and 3.0 $\mu \mathrm{m}$ (d95) [0.4 $\mu \mathrm{m}$ (d10) means that $10 \%$ of the powder presents a diameter of $0.4 \mu \mathrm{m}$ or below. The same analogy is used to explain d50 and d95]. Throughout this work, LSCF 6428 hollow fibres prepared by using uniform particle sizes are referred to as "smooth surface", and the ones prepared by using the mixture of particle with different sizes are referred to as "rough surface". By modifying the membrane surface, the surface 
oxygen exchange reaction might be altered, resulting in a modification of the oxygen permeation flux (Zydorczak et al., 2009).

\subsection{Characterization of the powder and hollow fibre membranes}

Three main characterization techniques were used in this work. X-ray diffraction (XRD) analysis using a PW3040/60 X-ray diffractometer (Philips Company) was used to characterize the crystal structure of the powders in a scan range $(2 \Theta)$ of 20-80 for both materials. A Quanta 200 (FEI Company) electron microscope was used for energy dispersive $\mathrm{X}$-ray emission analysis (EDAX) to confirm the constituent metal cation stoichiometry of the powders and membranes. The same instrument was used in scanning electron microscopy (SEM) studies in order to ascertain morphology and particle size of the powders and to investigate the surface microstructure of the hollow fibre membranes. These characterizations are always indicated when a new batch of ceramic powder or ceramic membrane is obtained. In addition, post characterization is also suggested for the used membranes in order to verify the integrity of their crystal phase, as well as their stoichiometry and morphology.

\section{RESULTS AND DISCUSSION}

\subsection{XRD analysis}

The crystalline structure of the powders and hollow fibre membranes were investigated by X-ray diffraction. In order to ascertain the crystal structure, diffractograms were obtained by this analysis and compared with known patterns reported in the literature.

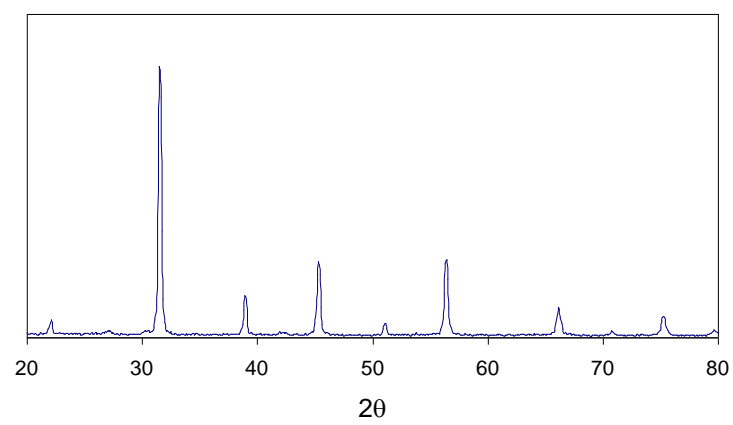

Figure 1. XRD powder patterns for the commercial BSCF 5582

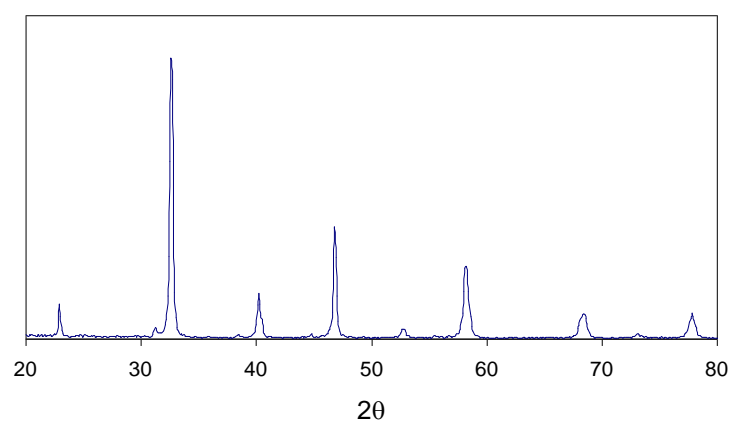

Figure 2. XRD powder patterns for the commercial LSCF 6428.

No calcination procedure was carried out on the commercial powders of BSCF 5582 and LSCF 6428. The powders were used without any treatment. Figure 1 shows the XRD powder pattern for the commercial BSCF 5582.

The result presented in Figure 1 was compared with the literature (Tan et al., 2003) showing a good agreement, which indicates that the BSCF 5582 powders synthesized in this work present a correct crystalline perovskite structure. In addition, Shao et al. (2000) have also investigated BSCF 5582 perovskite and have obtained a XRD pattern that is similar to the structure corresponding to cubic perovskite with the lattice parameter $a=3.9795 \AA$.

The other material investigated in this work was the commercial LSCF 6428. Similarly to the commercial BSCF 5582, the LSCF 6428 was also used without any treatment. Figure 2 presents the XRD powder pattern for this material.

The commercial LSCF 6428 also demonstrated a single-phase perovskite structure, as can be seen in Figure 2.

BSCF 5582 and LSCF 6428 hollow fibre membranes were prepared by a combined phaseinversion/sintering technique in collaboration with the Department of Chemical Engineering \& Chemical Technology, at the Imperial College / London. Because a polymer solution was added to the powder during the fabrication procedure of the hollow fibre membranes, an XRD analysis of the membranes was performed in order to certify that the original perovskite structure was retained.

Figures 3 and 4 show the XRD analysis for the BSCF 5582 and LSCF 6428 hollow fibres, respectively. 


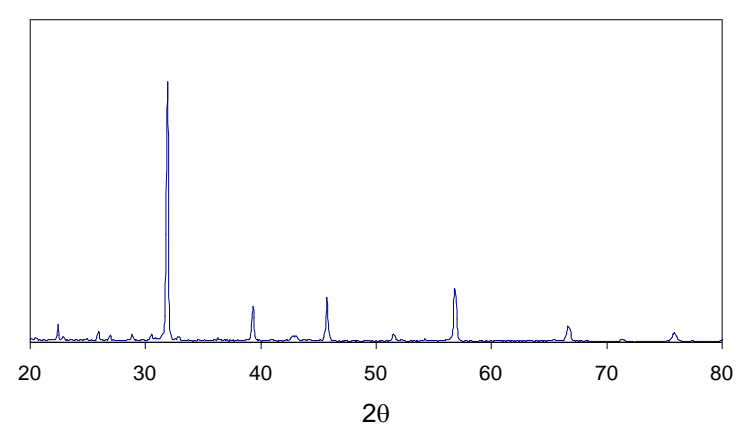

Figure 3. XRD analysis for the BSCF 5582 hollow fibre.

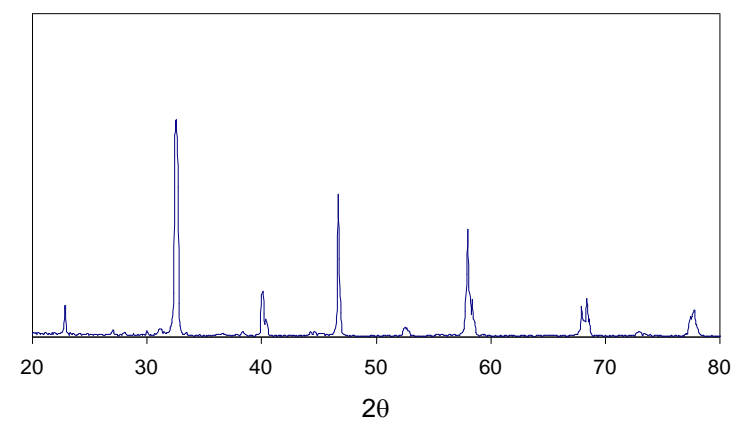

Figure 4. XRD analysis for the LSCF 6428 hollow fibre.

As can be seen in Figures 3 and 4, clear peaks were observed in the 2-tetha range studied. Comparing these results with the respective XRD powder pattern results (Figures 1 and 2), peaks at the same 2-tetha angle position were obtained. The patterns present a slight noise when compared with the XRD powder pattern which might indicate a lowering of the crystal symmetry. However, the perovskite structure could still be retained.

The XRD results presented in Figure 4 refers to LSCF 6428 with a smooth and rough surface. As the difference between the two LSCF 6428 is only the particle size used during its preparation, the XRD results for the two hollow fibres should not differ.

\subsection{SEM analysis}

The morphology of the BSCF 5582 and LSCF 6428 powders and hollow fibres were ascertained by SEM analysis. The morphology study of membranes plays an important role in predicting their performance. Zhang et al. (1999) reported that, for membranes with the same components, the oxygen permeation flux increases when decreasing its average grain size.

Figure 5 shows the SEM images for the BSCF 5582 and LSCF 6428 powder synthesized by CSP. The SEM results demonstrate that the commercial BSCF 5582 (Figure 5a) and LSCF 6428 (Figure 5b) powders reveal small particles with an uniform distribution.

SEM micrographs of the hollow fibres were also taken in order to investigate their morphologic structure. A fingerprint-like picture of the hollow fibres could be obtained by using this technique showing some features such as particle size, grain boundaries, and formation of agglomeration and cavities, which can be later associated with their performance. Figure 6 shows the SEM images of the BSCF 5582 membrane.

Figure 6a shows that the outer diameter (OD) and the inner diameter (ID) of the BSCF 5582 hollow fibre are $1.70 \mathrm{~mm}$ and $1.32 \mathrm{~mm}$, respectively. The outer surface of the hollow fibre (Figure 6b) presents large plates of approximately 40-50 $\mu \mathrm{m}$ in diameter with small grains with diameter lower than $5 \mu \mathrm{m}$, distributed over its surface. The grain boundaries are not completely
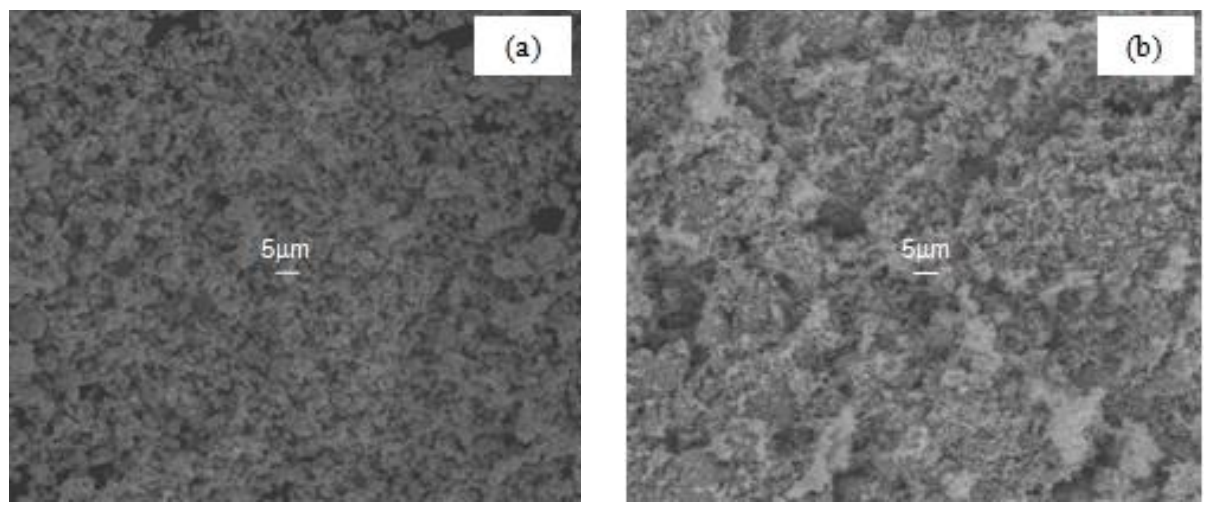

Figure 5. SEM images of (a) BSCF 5582 powders synthesized by CSP and (b) LSCF 6428 powders synthesized by CSP. 

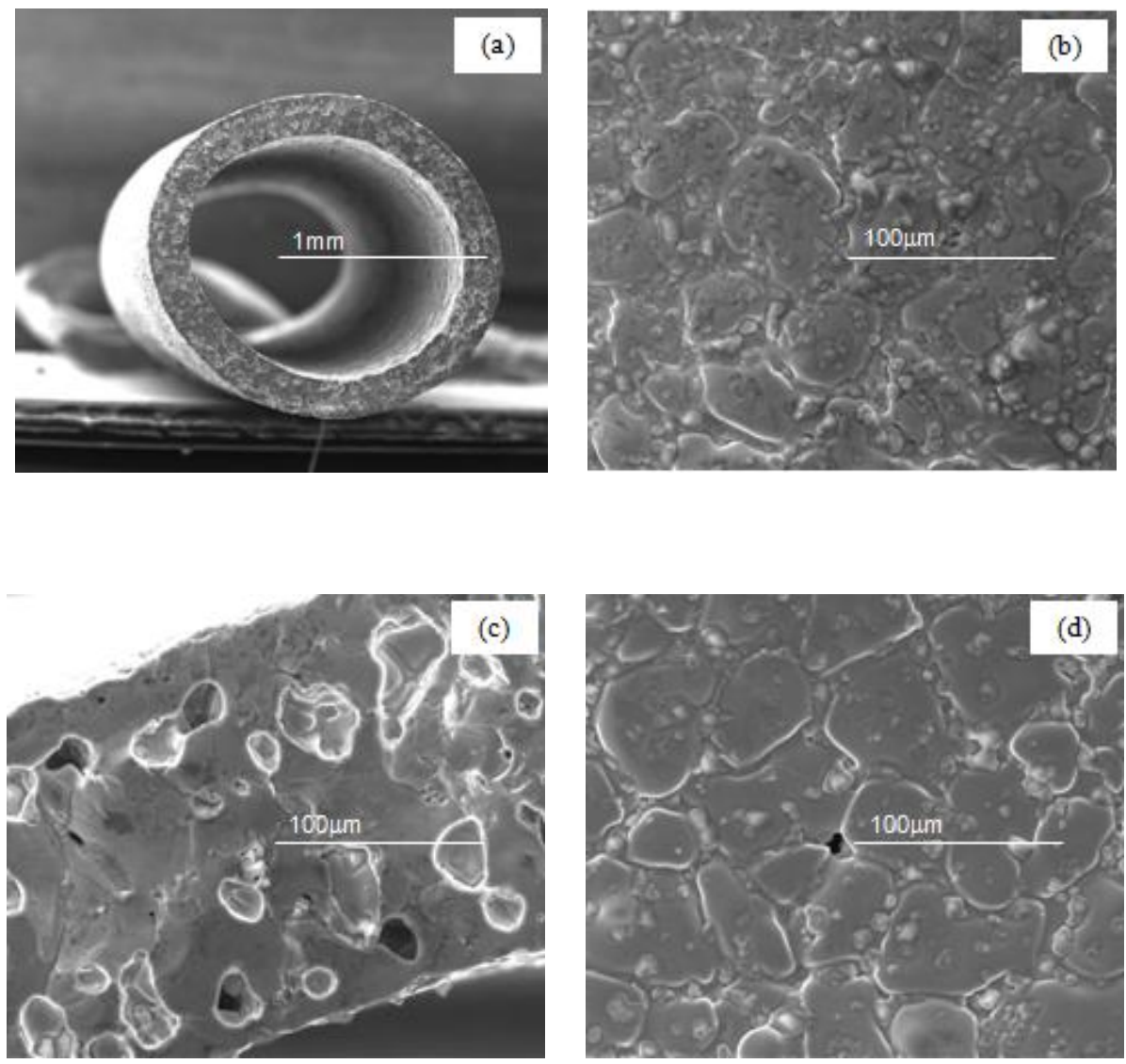

Figure 6. SEM images of the BSCF 5582 (a) hollow fibre, (b) outer surface, (c) cross-section and (d) inner surface.

clear and some small cavities are presented. In the cross-section image (Figure 6c), a large distribution of holes can be observed, which might be a concern for obtaining a gas-tight membrane. The inner surface shown in Figure $6 \mathrm{~d}$ indicates a structure similar to the outer surface with cavities of $c a 12 \mu \mathrm{m}$ in diameter.

The second hollow fibre studied in this work is the LSCF 6428. The SEM micrographs for the LSCF 6428 with a smooth surface are presented in Figure 7.

It can be seen from Figure 7a that the LSCF 6428 with a smooth surface presents an OD of $1.70 \mathrm{~mm}$ and an ID of $1.17 \mathrm{~mm}$. Figure $7 \mathrm{~b}$ shows the outer surface of the hollow fibre. In this figure, grains below $2 \mu \mathrm{m}$ in diameter are observed which are much smaller than those of the BSCF 5582 presented in Figure $6 \mathrm{~b}$. The cross-section of the hollow fibre (Figure 7c) presents a structure filled with elongated finger-like cavities close to both outer and inner surface. These cavities are enclosed by a thin dense layer of the same membrane material. By removing this thin dense layer or synthesizing the hollow fibre without it, one could provide a higher surface area which could also be of interest for catalyst impregnation. However, removal of such layer or modification of the hollow fibre synthesis was not investigated in this work. A dense structure free of porous cavities between the outer and inner surface can also be observed in Figure 7c, which could still sustain a gas-tight hollow fibre in the case of removal of the membrane "skin". The inner surface presented in Figure $7 \mathrm{~d}$ shows grains with diameters below $2 \mu \mathrm{m}$, similarly to the outer surface.

Finally, the third hollow fibre studied was the LSCF 6428 with a rough surface (Figure 8).

From Figure 8a, it can be observed that the LSCF 6428 hollow fibre with a rough surface has an OD of $1.57 \mathrm{~mm}$ and an ID of $0.96 \mathrm{~mm}$, which is slightly smaller than the LSCF 6428 with a smooth surface shown in Figure 7a. The difference in the OD and ID might be associated with the shrinkage of the materials. It can also be observed in Figure 8 a that 

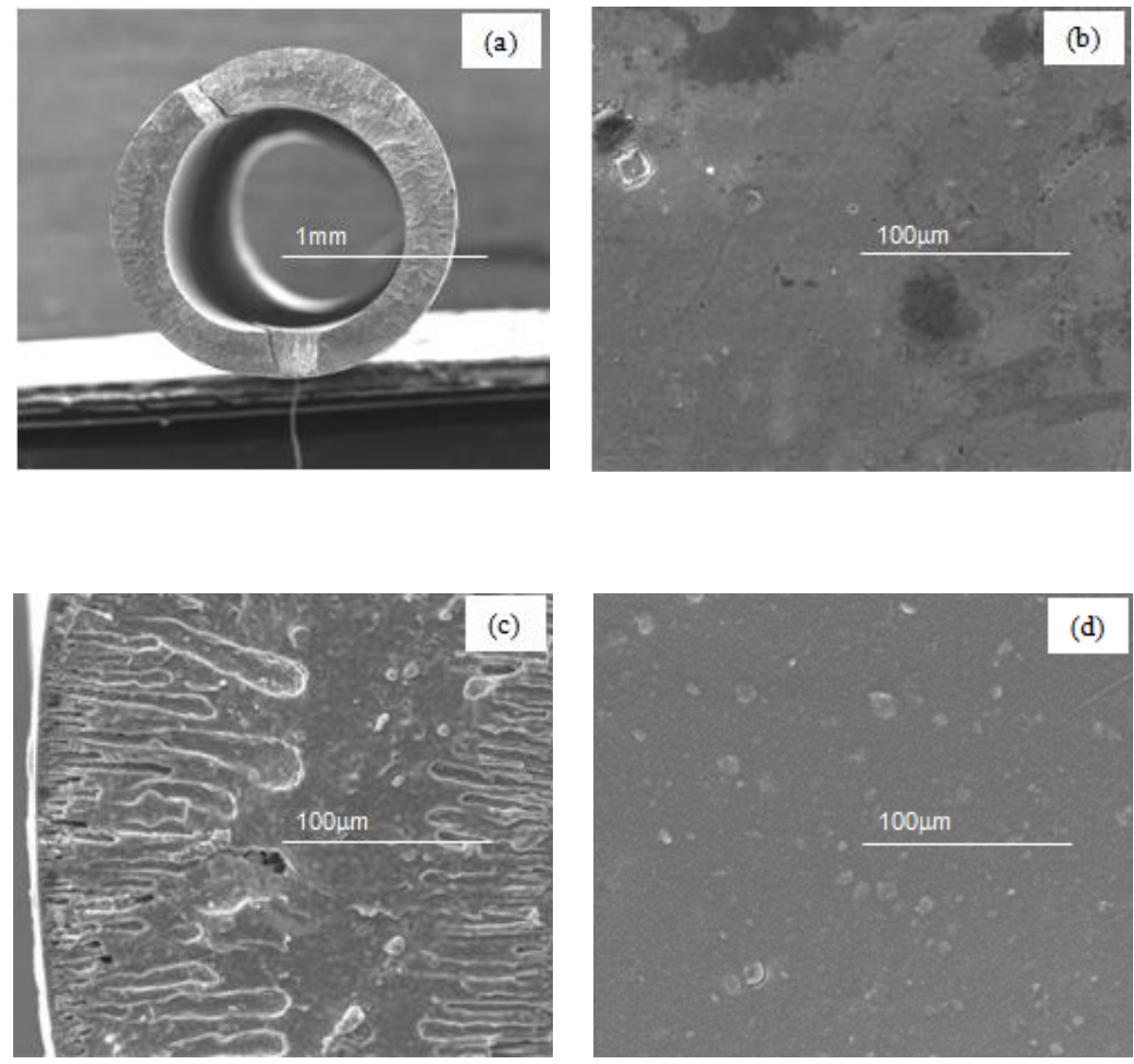

Figure 7. SEM images of the LSCF 6428 with a smooth surface (a) hollow fibre, (b) outer surface, (c) cross-section and (d) inner surface.

a reasonably porous structure is present. Therefore, in this case, it is extremely important to run a leak test in order to confirm that the membrane is truly gas-tight. Figure $8 \mathrm{~b}$ shows the outer surface of the LSCF 6428 with a rough surface which seems to be moderately rugous. The grain boundaries are not well defined, which impairs the measurement of the grain size. The cross-section of the LSCF 6428 with a rough surface is presented in Figure $8 \mathrm{c}$. Similarly to the LSCF 6428 with a smooth surface, elongated finger-like cavities are observed. However, its structure is fairly spongy. Cavities with diameter below $2 \mu \mathrm{m}$ are also observed in the inner surface of the LSCF 6428 with a rough surface, as shown in Figure $8 \mathrm{~d}$.

Tan et al. (2008) have reported that the oxygen permeation fluxes through the hollow fibre membranes might be improved by surface modifications. Therefore, the results reported in this work indicate that better oxygen permeation is expected when working with LSCF 6428 with a rough surface.

\subsection{EDAX analysis}

This technique was used to determine the elemental composition of the powders and pellets. It is a bulk technique in which an electron beam of variable spot size is used to analyze a volume of the sample extending to beneath the surface. In this study the lowest spot size used to analyze the finer details of the samples was of the order of $1 \mu \mathrm{m}^{2}$ with a penetration depth of about $1 \mu \mathrm{m}$, which means that a volume of mixed metal oxide of approximately $1 \mu \mathrm{m}^{3}$ was analyzed.

The EDAX results for the powder of BSCF 5582 and LSCF 6428 synthesised by CSP showed an amount of carbon of $3.33 \%$ and $2.57 \%$, respectively. It is important to notice that the commercial powders of BSCF 5582 and LSCF 6428 were used without any treatment. Probably, any carbon found in the samples came from contamination during the synthesis or during handling. 

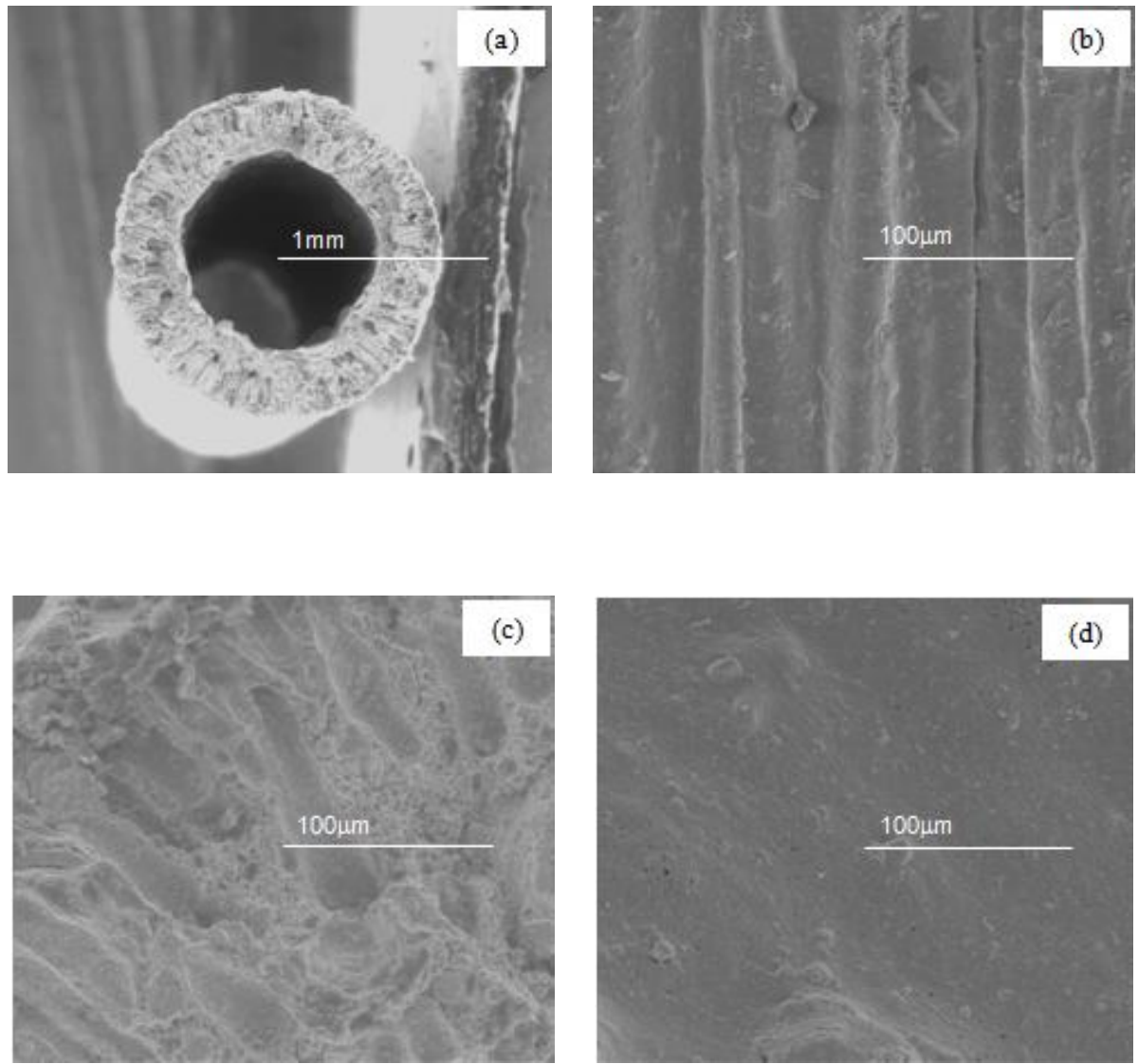

Figure 8. SEM images of the LSCF 6428 with a rough surface (a) hollow fibre, (b) outer surface, (c) cross-section and (d) inner surface.

Qualitative and quantitative analyses on the hollow fibres were also performed by EDAX analysis. According to the EDAX results for the BSCF 5582 hollow fibre, trace amounts of sulphur and calcium were observed on its composition. This might be due the additives introduced during the fabrication of the hollow fibres or contamination during the fabrication process.

From the EDAX results for the LSCF 6428 hollow fibres with a smooth and rough surface, it could be noticed that no sulphur or calcium were present on the structure of these membranes. In contrast, a small amount of carbon was observed on both membranes. The carbon presented on both LSCF hollow fibres was possibly due to incomplete sintering process or due to contamination after its preparation.

The nominal ratio and the experimental stoichiometry of the BSCF 5582 and LSCF 6428 hollow fibres are shown in Table 1.

As can be seen from Table 1, there are some discrepancies between the nominal ratio and the

Table 1. Nominal ratio versus experimental stoichiometry for the BSCF 5582 and LSCF 6428 hollow fibre membranes.

\begin{tabular}{ccc}
\hline $\begin{array}{c}\text { Hollow fibre } \\
\text { membranes }\end{array}$ & $\begin{array}{c}\text { Nominal ratio } \\
\text { Ba:Sr:Co:Fe or La:Sr:Co:Fe }\end{array}$ & $\begin{array}{c}\text { Experimental } \\
\text { stoichiometry }\end{array}$ \\
\hline BSCF 5582 & $0.50: 0.50: 0.80: 0.20$ & $0.60: 0.57: 0.70: 0.17$ \\
$\begin{array}{c}\text { LSCF 6428 } \\
\text { (smooth surface) } \\
\text { LSCF 6428 }\end{array}$ & $0.60: 0.40: 0.20: 0.80$ & $0.63: 0.42: 0.33: 0.75$ \\
(rough surface) & $0.60: 0.40: 0.20: 0.80$ & $0.64: 0.40: 0.37: 0.77$ \\
\hline
\end{tabular}


experimental stoichiometry of the hollow fibres studied in this work. As explained earlier, EDAX analysis is a bulk technique where only a small volume of the sample is analyzed (around $1 \mu \mathrm{m}^{3}$ ). Therefore, it is difficult to obtain a representative quantification of the elements.

It could be observed from preliminary leak tests using helium and air on each side of the hollow fibres (not shown) that the BSCF 5582 hollow fibre membrane is not gas-tight. In addition, as explained earlier, some impurities were observed on the powder material and the membrane itself which could implicate in lower performance of the membranes. Therefore, their preparation procedure still needs to be improved before using them in partial oxidation. In contrast, the LSCF 6428 hollow fibre membrane was gas-tight. Although some carbon was observed on its surface, the perovskite structure was still retained, which could still be useful in the production of pure oxygen when using ceramic membrane reactors.

\section{CONCLUSIONS}

According to the results obtained by XRD, SEM and EDAX analysis of the powders and hollow fibre membranes, the LSCF 6428 membrane material was considered to be suitable for oxygen permeation experiments and partial oxidation reactions since no leaks were observed and the perovskite structure was obtained.

From the characterization results, higher oxygen permeation rates are expected, which consequently help improving the rates of partial oxidation reactions when working with the LSCF 6428 hollow fibres with a rough surface due to their higher surface area, which enhances oxygen desorption. This would improve the transformation of natural gas into liquid chemical products free of sulphur and aromatics. The reduction of such impurities in liquid fuels is a worldwide tendency due to the impact on human health and the environment. In addition, the LSCF 6428 hollow fibres with a rough surface present a fairly spongy structure which might be of interest in catalyst impregnation and surface kinetic studies.

\section{ACKNOWLEDGMENTS}

LCLS would like to thank CAPES for financial support. The authors would like to acknowledge Professor Kang Li for providing the hollow fibres and also Professor lan Metcalfe and Dr. Alan Thursfield for their help with various aspects of this work.

\section{NOMENCLATURE}

BSCF $5582-\mathrm{Ba}_{0.5} \mathrm{Sr}_{0.5} \mathrm{Co}_{0.8} \mathrm{Fe}_{0.2} \mathrm{O}_{3-\delta}$ CCP - Cubic close-packing

CSP - Combustion spray pyrolysis

EDAX - Energy dispersive $X$-ray emission analysis

ID - Inner diameter

LSCF $6428-\mathrm{La}_{0.6} \mathrm{Sr}_{0.4} \mathrm{Co}_{0.2} \mathrm{Fe}_{0.8} \mathrm{O}_{3-\delta}$

$\mathrm{OD}$ - Outer diameter

POM - Partial oxidation of methane

SEM - Scanning electron microscopy

STP - Standard condition for temperature and pressure ( $20 \stackrel{\circ}{ } \mathrm{C}$ and $1 \mathrm{~atm})$

Syngas - Synthesis gas

XRD - X-ray diffraction

\section{REFERENCES}

Dong, H.; Shao, Z.; Xiong, G.; Tong, J.; Sheng, S.; Yang, W. Investigation on POM reaction in a new perovskite membrane reactor. Catal. Today, v.67, p. 3-13, 2001. doi:10.1016/S0920-5861(01)00277-2

Gellings, P. J.; Bouwmeester, H. J. M. Ion and mixed conducting oxides as catalysts. Catal. Today, v.12, p. 1-101, 1992. doi:10.1016/09205861(92)80046-P

Jin, W.; Li, S.; Huang, P.; Xu, N.; Shi, J.; Lin, Y. S. Tubular lanthanum cobaltite perovskite-type membrane reactors for partial oxidation of methane to syngas. J. Membr. Sci., v.166, p. 13-22, 2000a. doi:10.1016/S0376-7388(99)00245-8

Jin, W.; Gu, X.; Li, S.; Huang, P.; Xu, N.; Shi, J. Experimental and simulation study on a catalyst packed tubular dense membrane reactor for partial oxidation of methane to syngas. Chem. Eng. Sci., v.55, p. 2617-2625, 2000b. doi:10.1016/S00092509(99)00542-4

Lane, J. A.; Benson, S. J.; Waller, D.; Kilner, J. A. Oxygen transport in $\mathrm{La}_{0.6} \mathrm{Sr}_{0.4} \mathrm{Co}_{0.2} \mathrm{Fe}_{0.8} \mathrm{O}_{3-\delta}$. Solid State lonics, v.121, p. 201-208, 1999. doi:10.1016/S0167-2738(99)00014-4 
Li, S.; Qi, H.; Xu, N.; Shi, J.; Tubular dense perovskite type membranes. Preparation, sealing, and oxygen permeation properties. Ind. Eng. Chem. Res., v.38, p. 5028-5033, 1999. doi:10.1021/ie990446s

Liu, S.; Tan, X.; Li, K.; Hughes, R. Preparation and characterization of $\mathrm{SrCe}_{0.95} \mathrm{Yb}_{0.05} \mathrm{O}_{2.975}$ hollow fibre membranes. J. Membr. Sci., v.193, p. 249-260, 2001. doi:10.1016/S0376-7388(01)00518-X

Mulder, M. Basic principles of membrane technology. Kluwer Academic Publishers, Netherdands, 1996.

Neiva, L. S.; Gama, L. A study on the characteristics of the reforming of methane: a review. Brazilian Journal of Petroleum and Gas, v.4, p. 119-127, 2010. doi:10.5419/bjpg2010-0013

Pei, S.; Kleefisch, M. S.; Kobylinski, T. P.; Faber, J.; Udovich, C. A.; Zhang-mccoy, V.; Dabrowski, B.; Balachandran, U.; Mieville, R. L.; Poeppel, R. B. Failure mechanisms of ceramic membrane reactors in partial oxidation of methane to synthesis gas. Catal. Lett., v.30, p. 201-212, 1995. doi:10.1007/BF00813686

Shao, Z.; Yang, W.; Cong, Y.; Dong, H.; Tong, J.; Xiong, G. Investigation of the permeation behavior and stability of a $\mathrm{Ba}_{0.5} \mathrm{Sr}_{0.5} \mathrm{Co}_{0.8} \mathrm{Fe}_{0.2} \mathrm{O}_{3-\delta}$ oxygen membrane. J. Membr. Sci., v.172, p. 177-188, 2000. doi:10.1016/S0376-7388(00)00337-9

Shao, Z.; Dong, H.; Xiong, G.; Cong, Y.; Yang, W. Performance of a mixed-conducting ceramic membrane reactor with high oxygen permeability for methane conversion. J. Membr. Sci., v.183, p. 181-192, 2001a. doi:10.1016/S03767388(00)00591-3

Shao, Z.; Xiong, G.; Tong, J.; Dong, H.; Yang, W. Ba effect in doped $\mathrm{Sr}\left(\mathrm{Co}_{0.8} \mathrm{Fe}_{0.2}\right) \mathrm{O}_{3-\delta}$ on the phase structure and oxygen permeation properties of the dense ceramic membranes. Sep. Purif. Technol., v.25, p. 419-429, 2001b. doi:10.1016/S13835866(01)00071-5

Shao, Z.; Xiong, G.; Dong, H.; Yang, W.; Lin, L. Synthesis, oxygen permeation study and membrane performance of a $\mathrm{Ba}_{0.5} \mathrm{Sr}_{0.5} \mathrm{Co}_{0.8} \mathrm{Fe}_{0.2} \mathrm{O}_{3-\delta}$ oxygen-permeable dense ceramic reactor for partial oxidation of methane to syngas. Sep. Purif. Technol., v.25, p. 97-116, 2001c. doi:10.1016/S1383-5866(01)00095-8
Tan, L.; Gu, X.; Yang, L.; Jin, W.; Zhang, L.; Xu, N. Influence of powder synthesis methods on microstructure and oxygen permeation performance of $\mathrm{Ba}_{0.5} \mathrm{Sr}_{0.5} \mathrm{Co}_{0.8} \mathrm{Fe}_{0.2} \mathrm{O}_{3-\delta}$ perovskitetype membranes. J. Membr. Sci., v.212, p. 157-165, 2003. doi:10.1016/S0376-7388(02)00494-5

Tan, X.; Liu, Y.; Li, K. Mixed conducting ceramic hollow-fiber membranes for air separation. AIChE J., v.51, p. 1991-2000, 2005. doi:10.1002/aic.10475

Tan, X.; Wang, Z.; Liu, H.; Liu, S. Enhancement of oxygen permeation through $\mathrm{La}_{0.6} \mathrm{Sr}_{0.4} \mathrm{Co}_{0.2} \mathrm{Fe}_{0.8} \mathrm{O}_{3-\delta}$ hollow fibre membranes by surface modifications. J. Membr. Sci., v.324, p. 128-135, 2008. doi:10.1016/j.memsci.2008.07.008

Teraoka, Y.; Zhang, H.-M.; Furukawa, S.; Yamazoe, N. Oxygen permeation through perovskite-type oxides. Chem. Lett., v.14, p. 17431746, 1985a. doi:10.1246/cl.1985.1743

Teraoka, Y.; Zhang, H.-M.; Yamazoe, N. Oxygensorptive properties of defect perovskite-type $\mathrm{La}_{1-\mathrm{x}} \mathrm{Sr}_{x} \mathrm{Co}_{1-y} \mathrm{Fe}_{y} \mathrm{O}_{3-\delta}$. Chem. Lett., v.14, p. 13671370, 1985b. doi:10.1246/cl.1985.1367

Thursfield, A.; Metcalfe, I. S. Methane oxidation in a mixed ionic-electronic conducting ceramic hollow fibre reactor module. J. Solid State Electrochem., v.10, p. 604-616, 2006. doi:10.1007/s10008-006-0139-6

Uhlhorn, R. J. R.; Burggraaf, A. J.; in: Bhave, R. R. (Eds.). Inorganic membranes: synthesis, characteristics and applications. Van Nostrand Reinhold, New York, 1991.

Wang, H.; Cong, Y.; Yang, W. Oxygen permeation study in a tubular $\mathrm{Ba}_{0.5} \mathrm{Sr}_{0.5} \mathrm{Co}_{0.8} \mathrm{Fe}_{0.2} \mathrm{O}_{3-\delta}$ oxygen permeable membrane. J. Membr. Sci., v.210, p. 259-271, 2002. doi:10.1016/S03767388(02)00361-7

Zhang, K.; Yang, Y. L.; Ponnusamy, D.; Jacobson, A. J.; Salama, K. Effect of microstructure on oxygen permeation in $\mathrm{SrCo}_{0.8} \mathrm{Fe}_{0.2} \mathrm{O}_{3-\delta}$. J. Mater. Sci., v.34, p. 1367-1372, 1999. doi:10.1023/A:1004518719410

Zydorczak, B.; Wu, Z.; Li, K. Fabrication of ultrathin $\mathrm{La}_{0.6} \mathrm{Sr}_{0.4} \mathrm{Co}_{0.2} \mathrm{Fe}_{0.8} \mathrm{O}_{3-\delta}$ hollow fibre membranes for oxygen permeation. Chem. Eng. Sci., v.64, p. 4383-4388, 2009. doi:10.1016/j.ces.2009.07.007 